\title{
Aplicação do método de Clarke e Wright na resolução de problemas de roteirização: um estudo de caso
}

Lucas Di Paula Gama dos Santos dipaula_9@hotmail.com

Universidade Federal do Vale do São Francisco (UNIVASF), Juazeiro, Bahia, Brasil

Wendell Ramon Barbosa Machado

wendell ramonsb@hotmail.com

Universidade Federal do Vale do São Francisco (UNIVASF), Juazeiro, Bahia, Brasil

Pedro Vieira Souza Santos

pedrovieirass@hotmail.com

Francisco (UNIVASF), Juazero do São

Juazeiro, Bahia,

Brasil
A logística de distribuição de produtos se resume em levar os produtos certos, ao lugar correto, no momento exato e com o nível de serviço desejado pelo consumidor, com o mínimo de custo possível e para tanto faz uso de metodologias heurísticas para construção de roteiros de entregas de produtos. Sabendo que toda organização é capaz fazer algumas intervenções que podem acarretar em soluções não eficientes, o que pode significar um aumento desproporcional dos custos logísticos. Nesse contexto, a logística desempenha papel importante no desenvolvimento da organização. Assim, visando a busca por melhorias no setor de logística de distribuição de uma empresa, esta pesquisa apresenta o uso de ferramentas de roteirização combinado ao sistema de informação geográfica para otimizar a entrega de produtos a partir de uma fábrica localizada na cidade de Petrolina-PE. Foi aplicada a heurística de Clarke e Wright e os resultados confirmaram êxito em sua aplicação no intuito de melhor a eficiência operacional mediante redução de deslocamentos dos veículos para atendimento às demandas na ordem de $40 \%$.

PALAVRAS-CHAVE: Heurística. Roteirização. Distribuição. 


\section{INTRODUÇÃO}

Ultimamente, devido à crescente competitividade entre as organizações, observa-se que é fundamental se ter uma operação que atenda as expectativas do cliente, reflexo de um nível de serviço adequado. Nesse contexto, a logística desempenha papel importante no desenvolvimento da organização. Para Ballou (2006), o termo "logística" é entendido como o processo de planejar, implantar e controlar o fluxo, de forma eficiente e eficaz, de materiais e informações. Bowersox (2001) complementa tal afirmação e cita a logística tem como objetivo principal auxiliar a empresa a criar valor para seus clientes, observando o menor custo possível.

Segundo Platt e Nunes (2007) a economia mundial desenvolveu-se com a assistência das atividades e conhecimentos logísticos. No entanto, os autores afirmam que a logística só veio ser estudada com profundidade a partir da 2 응 guerra mundial, onde de fato buscou-se embasamento científico para que pudesse aprimorar as estratégias logísticas, fato este necessário para a época.

Os conhecimentos logísticos desenvolvidos naquela época são utilizados até hoje nos diversos segmentos econômicos. Contudo, os poucos investimentos em capacitação de pessoal, sistemas de rastreabilidade, automação dos sistemas envolvidos e os fatores externos (estradas, combustível, incentivos públicos) interferem diretamente setor logístico, tornando-o muitas vezes oneroso (MICHEL et al., 2011).

Novaes (2007) chama atenção para a falta de uma estrutura organizacional adequada que limitam o avanço da logística no escoamento da produção no Brasil. Para Barth e Michel (2012), o setor logístico nacional sofre com problemas crônicos como estradas ultrapassadas, elevado custo de combustíveis, como também o alto investimento no transporte rodoviário em detrimento aos outros modais.

Assim, a atividade de distribuição (inerente à logística) apresenta oportunidades diversas para as empresas, apesar do seu custo elevado devido a deficiências ligadas a infraestrutura local. Mesmo assim, tem sido foco das organizações para obtenção de vantagem competitiva por meio de otimização do processo (BERTAGLIA, 2009).

Nesse sentido, a busca por otimizar os processos logísticos locais tem ganhado importância do ponto de vista da sobrevivência e manutenção da vantagem competitiva, onde diversas organizações preocupam-se com este tema. Arbache et al. (2004), destacam que a distribuição refere-se a operações que ocorrem com os produtos chamados "acabados", responsabilizando-se desde o armazenamento até o instante em que são entregues ao ponto de consumo final, atendendo aos pedidos feitos.

Para tanto, atualmente, o anseio por melhorar o desempenho em sua forma operacional do processo de entrega dos produtos acabados, a técnica de roteirização surge como instrumento capaz de otimizar o planejamento deste setor. Para Laporte et al. (2002), ao se falar em roteirização, deve-se associar a definição basicamente de roteiros ótimos para os veículos e/ou frota da empresa, sempre de modo a minimizar o custo de atendimento as demandas. Além disso, deve-se assegurar que os locais sejam atendidos em sua totalidade, observando a capacidade do veículo. Araújo (2003) sintetiza o conceito e afirma que roteirização é a capacidade de determinar a melhor sequência a ser obedecida, em tese, para que a frota percorra e assegure o atendimento às demandas. 
Logo, o presente estudo pôde ser feito em uma dessas empresas que buscam melhorar a roteirização local, através do método de Clarke e Wright, onde tem como fundamento básico aproveitar a oportunidade de economia que se pode ter quando se analisa sob uma nova ótica as rotas existentes na empresa (OSMAN, 1993).

A organização industrial do presente estudo tem sua matriz localizada na cidade de Petrolina/PE e atua no ramo de produção e distribuição de picolés e sorvetes e atende uma significativa parte da região Nordeste. A fábrica declara dotar de instalações e equipamentos modernos para a produção dos sorvetes, no entanto, é consciente da necessidade de buscar continuamente, minimização dos impactos causados pelos problemas logísticos do Brasil, mediante uso de metodologias de gestão de processos de distribuição de produtos a fim de manter o menor custo operacional.

Neste arsenal de conhecimentos é possível empregar métodos heurísticos de roteirização de entregas e minimizar custos que consoante Gama (2011), o objetivo da roteirização é obter rotas que minimizem custos de distribuição de uma frota de veículos operando a partir de um ou mais depósitos centrais.

Dentre os métodos de roteirização, destaca-se o de Clarke e Wright, que conforme Ballou (2006) tem capacidade indicada para aplicar-se na resolução de uma gama de situações que apresentam restrições práticas, sendo relativamente rápido, em termos de processamento computacional, indicado assim para situações com uma quantidade média de paradas, e capaz de gerar soluções que são quase ótimas. Ainda segundo o autor, a ideia de se aplicar o método das economias é minimizar a distância total percorrida por todos os veículos e posterior redução do número de veículos necessários para servir a todas as paradas.

Logo, o presente artigo teve como objetivo construir roteiros, empregando o método de Clarke e Wright de forma a atender a demanda com menores custos sem prejuízo no nível de serviço.

\section{ABORDAGEM TEÓRICA}

\section{LOGÍSTICA}

Nos dias de hoje, com o fenômeno da globalização, os negócios adquiriram um ritmo muito mais acelerado e dinâmico. Neste cenário, as empresas competem não apenas em âmbito local como também globalmente. Com isso, observou-se um crescimento expressivo na competição internacional e no comércio global (DALMÁS, 2008). Portanto, para se manterem, as empresas precisam ser mais flexíveis e apresentar respostas rápidas ao mercado. Para isso, é necessário que elas desenvolvam um sistema de logística eficiente, capaz de torná-las mais competitivas (SANTOS; FELIX; VIEIRA, 2012).

Gasnier (2002, p. 17) define o termo "Iogística" como:

[...] o processo de planejar, executar e controlar o fluxo e armazenagem de forma eficaz e eficiente em termos de tempo, qualidade e custos, de matérias primas, materiais em elaboração, produtos acabados e serviços, bem como as informações correlatas, desde o ponto de origem até o ponto 
de consumo (cadeia de suprimentos), com o propósito de assegurar $o$ atendimento das exigências de todos os envolvidos, isto é, clientes, fornecedores, acionistas, governo, sociedade e meio ambiente.

Complementando, Bowersox e Closs (2007), afirmam que o objetivo da logística é tornar disponíveis produtos e serviços no local onde são necessários, no momento em que são desejados. Envolve a integração de informações, transporte, estoque, armazenamento, manuseio de materiais e embalagens. $O$ objetivo central da logística é atingir um nível desejado de serviço ao cliente pelo menor custo possível.

Para Ballou (2006) a logística trata de todas as atividades de movimentação e armazenagem, que facilitam o fluxo de produtos desde o ponto de aquisição da matéria-prima até ao ponto de consumo final, assim como dos fluxos de informação que colocam os produtos em movimento, com o propósito de providenciar níveis de serviço adequados aos clientes a um custo razoável. Christopher (2011) completa esta afirmação e cita que a logística faz parte do processo estratégico da organização, almejando sempre rentabilidade do processo a nível máximo.

Pereira e Ronconi (2004) realizaram um estudo referente aos modelos de distribuição física em indústria alimentícia, em que a partir deste, foi possível identificar pontos a serem melhorados no sistema de distribuição física da empresa, utilizando técnicas de pesquisa operacional, através do desenvolvimento de um modelo que aperfeiçoasse a distribuição dos estoques ao longo da cadeia, mitigando os custos logísticos e aumentando o nível do serviço.

A logística, portanto, engloba todas as movimentações e estocagens de materiais tanto no ambiente interno fabril quanto na parte externa que vai da fábrica de origem até o consumidor final e em uma organização é primordial para que a mesma se destaque no mercado de trabalho (SANTOS; FELIX; VIEIRA, 2012).

Assim, o processo que conecta a origem ao seu destino final que seria o consumidor, é conhecido na logística como distribuição física, que tem como objetivo garantir que o produto certo seja entrega no local certo, no momento certo, atendendo as necessidades e desejos do cliente.

\section{DISTRIBUIÇÃO FÍSICA}

O objetivo principal da distribuição física é levar os produtos certos, ao lugar correto, no momento exato e com o nível de serviço desejado pelo consumidor, com o mínimo de custo possível (NOVAES, 2007). Bertaglia (2009, p. 33) afirma que "a distribuição é um processo que está normalmente associado ao movimento de material de um ponto de produção ou armazenagem até o cliente".

Santos, Felix e Vieira (2012) alegam que a distribuição física abrange os processos de estocar, transportar, controlar, troca de dados e fluxo financeiro permitindo transferir produtos desde o fabricante até o consumidor final. Kaminski (2004) relata que essas atividades assumem um papel estratégico essencial na conquista e fidelização dos clientes. Ching (2001) chama atenção para a importância que se deve ter em relação ao processo de distribuição devido 
a este ser uma frente de trabalho que impacta em todas as atividades logísticas, pois está ligada a atendimento de demandas dos clientes.

Chaberek (2002) enfatiza que a distribuição, assim como outras funções deve fazer parte da política estratégica da empresa e que esta permita, sobretudo, focalizar as necessidades dos seus clientes, devendo ainda dedicar-se ao gerenciamento integral dos processos. Silva (2015) afirma que um dos fatores que influenciam na distribuição dos produtos são as características e necessidades específicas do carregamento transportado, dentre elas destacam os de sensibilidade térmica.

Segundo Prado e Barros (2014) os produtos com sensibilidade térmica são transportados em quatro categorias distintas, dependendo do estado que os mesmos se encontram, sendo geralmente identificado de fresco a ultracongelado, onde temperatura é específica para cada mercadoria e variações da mesma durante estágios que compõem a cadeia de suprimento podem deteriorar o produto. Neste artigo, será representada a distribuição física dos produtos da empresa estudada.

\section{ROTEIRIZAÇÃO}

De acordo com Gama (2011), o sistema de distribuição física possui como elemento a roteirização de veículos de entrega. Ele afirma que o objetivo da roteirização é obter rotas que minimizem custos de distribuição de uma frota de veículos operando a partir de um ou mais depósitos centrais.

Corroborando, Belfiore e Fávero (2006) citam que o problema de roteirização de veículos (Vehicle Routing Problem - VRP) busca definir um agrupado de rotas considerando o menor custo possível, de forma que as rotas iniciem e terminem no ponto de origem (depósito, centro de distribuição, etc.), de forma que a demanda de todos os nós é considerada.

Conforme Conceição et al. (2004), a roteirização baseada na experiência humana, mesmo com a experiência de profissionais conhecedores do trânsito e da geografia local, ainda produz rotas com distâncias maiores que as rotas sugeridas pelos métodos heurísticos.

Portanto, a roteirização dos veículos acabou se tornando um problema, necessitando de soluções que minimizem os custos. Novaes (2007) afirma que um problema real de roteirização é definido por três fatores: decisões, objetivos, e restrições. As decisões dizem respeito ao arranjo de um grupo de clientes, que devem ser visitados, a um conjunto de veículos e respectivos motoristas, envolvendo também a programação e o sequenciamento das visitas. Como objetivos principais, satisfazer as necessidades do cliente, com os custos operacionais e de capital, tão baixos quanto possível. Por outro lado, deve obedecer a certas restrições como completar as rotas com os recursos disponíveis, respeitar os limites de tempo impostos pela jornada de trabalho dos motoristas e ajudantes.

Sendo assim, há um aumento da complexidade das ações de roteirização de veículos nas situações de mercado atual, com muitas variáveis e restrições. A solução ótima para tal problema acaba se tornando inviável, devido a não resolução em tempo aceitável pelos computadores (WU, 2007). A fim de se ter uma boa solução com um tempo razoavelmente pequeno, utiliza-se soluções baseadas em heurísticas. Santos e Leal (2007) asseguram que das heurísticas 
mais utilizadas para resolver o problema do VRP é o conhecido algoritmo de Clarke e Wright.

O estudo de Luna, Bellomusto e Monho (2015) aplicaram programa de roteamento de veículos em empresa do setor alimentício utilizando o método de Clarke e Wright apresentou bons resultados. Mostraram que a melhor organização das informações relativas aos clientes e a definição das rotas e sequencia das entregas com o uso de técnicas de otimização, contribui para a redução nos custos e tempo necessário a realização das atividades de distribuição.

Em outra pesquisa, Rodrigues et al. (2005) implementaram o método, apoiando diariamente a tomada de decisão em uma transportadora de médio porte numa operação de distribuição de produtos de aço na Grande São Paulo. Com a utilização foi obtida uma projeção de economia de 16 caminhões ou uma economia de $13,62 \%$ em relação ao custo total de transporte. Através desses e outros trabalhos, pode-se mostrar que os benefícios oriundos com a roteirização de veículos podem compensar o esforço na implementação dessa ferramenta mesmo em pequenas instâncias.

\section{MÉTODO CLARKE E WRIGHT - MCW}

A heurística de economias de Clarke e Wright (1964) apresenta bons resultados em problemas de roteirização de veículos. Segundo Ballou (2006) este método, tem flexibilidade suficiente para resolver um grande número de restrições práticas, sendo relativamente rápido, em termos computacionais, para problemas com um número moderado de paradas, e capaz de gerar soluções que são quase ótimas.

Conforme Novaes (2007, p. 313) o objetivo do método, como a maioria dos outros, é "gerar roteiros que respeitem as restrições de tempo e de capacidade, mas visando, ao mesmo tempo, minimizar a distância total percorrida pela frota." Para Cordeau et al. (2002), a implementação desta metodologia é simples e atrai pela velocidade de processamento e facilidade de codificação.

O algoritmo é um do $\mathrm{MCW}$, não fornecem uma solução ótima para o problema de segurança. $O$ método, no entanto produz uma relativamente boa solução. Isto é, uma solução que se desvia pouco a partir da solução ótima (LYSGAARD, 1997). Segundo Ballou (2006), o método de Clarke e Wright reduz esse nível a $2 \%$ do ótimo absoluto.

Entretanto, de acordo com Faulin, Sarobe e Simal (2005), a grande relevância de metodologias tratadas sobre algoritmos e abordadas por Clarke e Wright (1964), está na possibilidade de verificar as alterações nos algoritmos que tornem uma situação de serem simulados sob o ponto de vista de vários parâmetros de distribuição, todos monitorados ao mesmo tempo, criando planos de rota e/ou transporte de acordo com requisitos mais precisos em relação aos clientes e o próprio sistema local. 


\section{METODOLOGIA}

O trabalho caracteriza-se como estudo de caso, que para Yin (2010, p. 39), trata-se de "[...] uma investigação empírica que investiga um fenômeno contemporâneo em profundidade e em seu contexto de vida real, especialmente quando os limites entre o fenômeno e o contexto não são claramente evidentes." O mesmo pretendeu investigar, de acordo com o contexto de uma indústria, a aplicação da metodologia de roteirização para resolução de problemas de transporte.

O presente estudo seguiu um fluxograma de atividades conforme ilustra a Figura 1. Destacamos as atividades referentes à identificação do problema, pesquisa bibliográfica sobre o tema, escolha e aplicação do método e finalmente análise dos resultados.

Figura 1 - Fluxograma de ações metodológicas

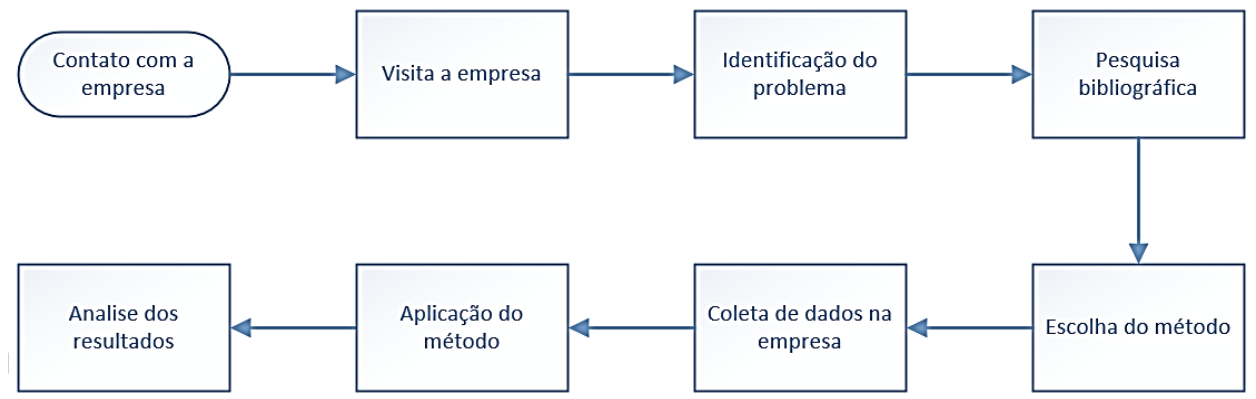

Fonte: Autores (2018)

Este trabalho se caracteriza como uma pesquisa quantitativa exploratória e segundo Fonseca $(2002$, p. 20), está centrada na objetividade e influenciada pelo positivismo, considera que a realidade só pode ser compreendida com base na análise de dados brutos. O método escolhido foi o algoritmo de Clarke e Wright, detalhado a seguir por Novaes (2007).

$\mathrm{O} \mathrm{MCW}$ baseia-se no conceito de ganho. Partimos da pior situação, em que um veículo sai (hipoteticamente) do centro de distribuição $-C D$, somente com a mercadoria destinada a um único cliente. Após fazer a entrega, o veículo volta ao depósito. Neste caso, supõe-se que um cliente $j$ seja atendido logo após a um primeiro cliente $i$, e o veículo faria as duas viagens na sequência mostrada na Figura 2.

Nesta primeira situação, Figura 2-a, sendo $d_{D, i}$ e $d_{D, j}$ as distâncias entre o CD e os clientes $i$ e $j$, o veículo faria um percurso para atendê-los igual a:

$$
L=2 \times d_{D, i}+2 \times d_{D, j}
$$

A segunda situação, Figura 2-b, representa uma possibilidade de melhoria desse esquema, onde os dois clientes $i$ e $j$ seriam juntados em um mesmo roteiro. Sendo assim, o veículo irá fazer o percurso igual a:

$$
L^{\prime}=d_{D, i}+d_{D, j}+d_{i, j}
$$


Ao integrar os clientes $i$ e $j$ num único roteiro, existirá uma economia, de percurso (ganho) igual à diferença entre $L$ e $L^{\prime}$, dado por:

$$
g_{i, j}=d_{D, i}+d_{D, j}-d_{i, j}
$$

O MCW se inicia com a análise de todas as combinações possíveis entre os nós, dois a dois. Em seguida, são ordenadas as combinações, na ordem decrescente dos ganhos $g_{i, j}$.

Figura 2 - Ilustração do conceito de ganho com a integração de dois clientes em roteiro compartilhado

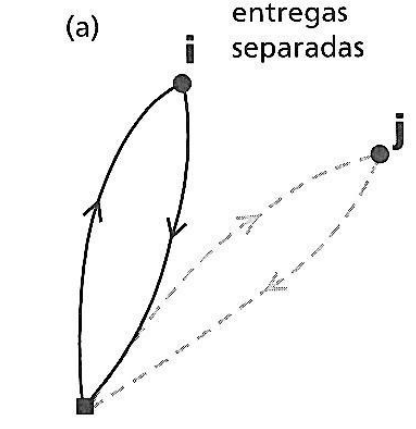

D (depósito)

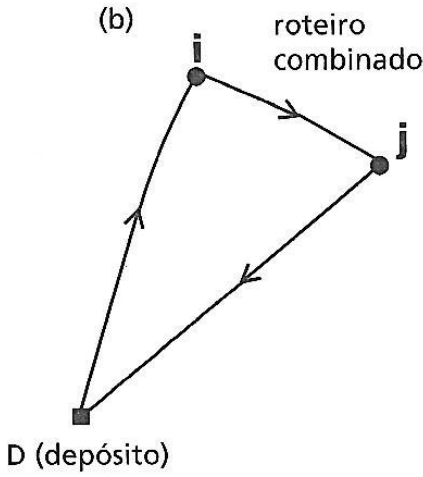

Fonte: Novaes (2007)

\section{RESULTADOS E DISCUSSÃO}

\section{CARACTERIZAÇÃO DA EMPRESA}

A empresa objeto do presente estudo é uma empresa que atua no ramo alimentício desde 1993, e tem como finalidade principal a produção e entrega de picolés e sorvetes de frutas. Está localizada na cidade de Petrolina-PE, região conhecida como Vale do São Francisco cuja economia se destaca na produção de frutas, principal, matéria prima para a produção dos produtos da instituição.

Outro ponto importante para o desenvolvimento da empresa na região do Vale é a elevada temperatura. Dentre todas as regiões brasileiras o Nordeste se destaca com as maiores médias de incidência de raios solares, fator fundamental para o desenvolvimento deste setor alimentício de frios (sorvetes e picolés) (BRASIL, 2003).

De acordo com as informações fornecidas pela empresa, esta possui modernas e amplas estruturas no segmento industrial de sorvetes. Sua frota conta com mais de 20 caminhões com unidades frigoríficas para transportes de sorvetes, 5 motos e 10 pick-ups. A linha de produção é preparada para atender todas as exigências de higiene necessárias para a produção e comercialização dos produtos com segurança e qualidade.

Possui sete diferentes produtos (Potes, Sublime, Supremo, Sundaes e copos, Copão, picolés e cones) e assim atende praticamente toda região do Vale do São Francisco e algumas localidades da região Nordeste. Seus clientes são grandes redes de supermercados, atacadistas, e empresas de menor porte como 
mercadinhos de bairro e pequenos estabelecimentos o que torna a necessária intensa distribuição.

\section{LOCALIZAÇÃO DOS CLIENTES}

As coordenadas geográficas foram levantadas e considera a empresa o centro de distribuição representado pelo ponto $(0,0)$ correspondendo a $(x, y)$. Os locais onde são destinados os produtos foram também representados em coordenadas geográficas e seus pontos expressaram o mesmo formato do centro de distribuição. Logo, esses dados estão relacionados na tabela a seguir.

Tabela 1 - Coordenadas geográficas dos pontos

\begin{tabular}{ccc} 
Ponto & Latitude & Longitude \\
D & 0,0000000 & 0,0000000 \\
Cliente 1 & $-0,0000064$ & 0,0000007 \\
Cliente 2 & 0,0050306 & $-0,0249889$ \\
Cliente 3 & $-0,0002056$ & $-0,0241333$ \\
Cliente 4 & 0,0234861 & 0,0308000 \\
Cliente 5 & $-0,0000694$ & $-0,0000306$ \\
Cliente 6 & 0,0011028 & 0,0049861 \\
Cliente 7 & $-0,0340444$ & 0,0161528 \\
Cliente 8 & $-0,0045794$ & 0,0128998 \\
Cliente 9 & 0,0134216 & $-0,0186042$ \\
Cliente 10 & 0,0401806 & $-0,0062542$ \\
Cliente 26 & $\ldots$ & $\ldots$ \\
Cliente 27 & $-0,0538924$ & 0,0216988 \\
Cliente 28 & $-0,0482734$ & $-0,0041782$ \\
Cliente 29 & $-0,0477034$ & 0,0180688 \\
Cliente 30 & $-0,0358384$ & $-0,0183252$ \\
Cliente 31 & $-0,0214954$ & 0,0010638 \\
\hline
\end{tabular}

Fonte: Autores (2018)

Após a formulação dos dados contidos na Tabela 1, é elaborada a matriz dos ganhos e ordenada em ordem decrescente, conforme Tabela 2.

Tabela 2 - Matriz de ganhos

\begin{tabular}{cc} 
Ordem & Pontos \\
1 & 14,57635 \\
2 & 12,39657 \\
3 & 11,77331 \\
4 & 11,73142 \\
5 & 11,66200 \\
$\ldots$ & $\ldots$ \\
460 & 0,00018 \\
461 & 0,00017 \\
462 & 0,00011 \\
463 & 0,00006 \\
464 & 0,00002 \\
465 & 0,00000 \\
\hline
\end{tabular}

Fonte: Os Autores (2018) 
A partir da matriz dos ganhos que demonstra a interação existente entre todos os pontos, foi possível gerar a Tabela 2 que representa a matriz dos ganhos de forma ordenada. A tabela 2, mostra em ordem decrescente, os valores, sendo o primeiro considerado mais interessante, diminuindo assim por diante o grau de importância.

\section{ROTEIRIZAÇÃO}

A etapa final do processo de roteirização plotada graficamente num plano cartesiano as rotas a partir da união dos pares de maior ganho obedecendo as restrições estabelecidas.

Figura 3 - Roteirização das entregas

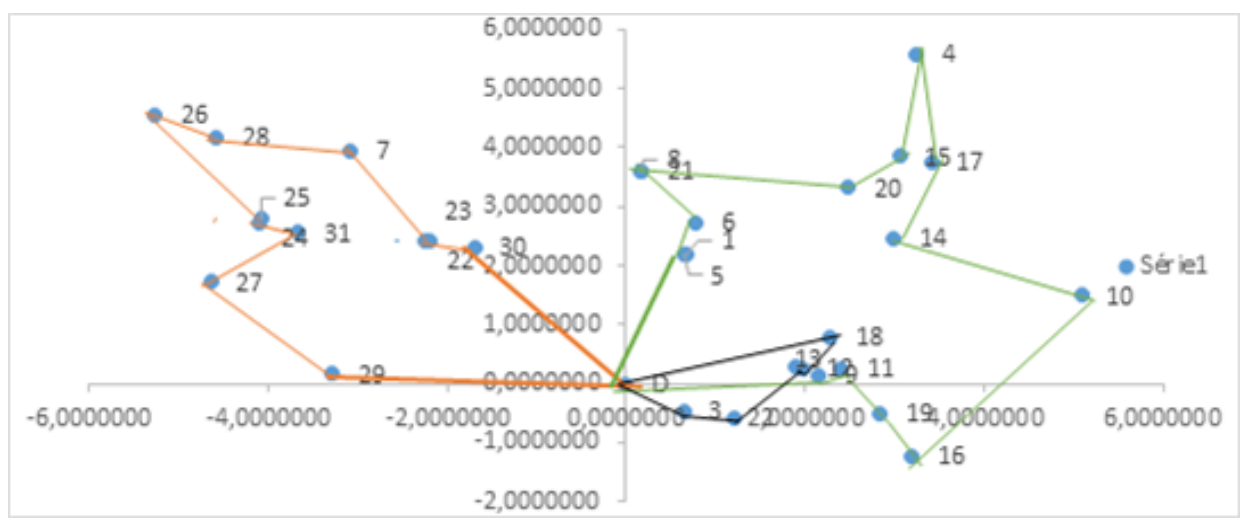

Fonte: Autores (2018)

De acordo com a Figura 3, estão descritas as 3 rotas designadas para as entregas num determinado dia comercial às cidades de Juazeiro e Petrolina. Cada rota foi construída progressivamente até o limite das restrições impostas e novas são iniciadas até que todos os clientes estejam integrados a uns dos roteiros. A construção até o limite da restrição maximiza a utilização dos recursos evitando ociosidade dos funcionários e frota de veículos.

Comparando-se os valores desenvolvidos pelo método heurístico de roteirização com os dados fornecidos pela empresa retratando a prática atual de entregas, perceber-se diferenças consideráveis.

Tabela 3 - Análise comparativa

$\begin{array}{ccc} & \text { Com Roteirização } & \\ & \text { Entregas juazeiro } & \text { Entregas Petrolina } \\ \text { Tempo (min) } & 268 & 430 \\ \text { Consumo (L) } & 5,03 & 6,46 \\ \text { Distância Percorrida (Km) } & 29,2 & 38,85 \\ & \text { Sem Roteirização } & \\ \text { Tempo (min) } & \text { Entregas juazeiro } & \text { Entregas Petrolina } \\ \text { Consumo (L) } & 502 & 763 \\ \text { Distância Percorrida (Km) } & 8,28 & 13,79 \\ \end{array}$

Fonte: Autores (2018) 
Os dados na Tabela 3 mostram a soma das três rotas sendo a rota 1 exclusiva para a cidade de Juazeiro e rotas 2 e 3 dedicadas à cidade de Petrolina.

Tabela 4 - Reduções

\begin{tabular}{ccc}
\hline & Entregas juazeiro & Entregas Petrolina \\
\hline Tempo (min) & $47 \%$ & $44 \%$ \\
Consumo (L) & $39 \%$ & $53 \%$ \\
Distância Percorrida (Km) & $39 \%$ & $51 \%$ \\
\hline
\end{tabular}

Fonte: Autores (2018)

Para verificar a efetividade do método, elaborou-se a Tabela 4 e constatouse uma redução dos quilômetros percorridos em $39 \%$ para a cidade de Juazeiro e 51\% para a cidade de Petrolina, o que já demonstra a eficiência do algoritmo de Clarke e Wright na busca de rotas que minimizam a distância percorrida. Além disso, ressaltam-se a diminuição expressiva do tempo de deslocamento de $47 \%$ e $44 \%$ e consumo de combustíveis de $39 \%$ e $53 \%$ para as cidades de Juazeiro e Petrolina, respectivamente.

\section{CONSIDERAÇÕES FINAIS}

Observando que toda empresa prioriza a qualidade dos serviços prestados e dos produtos entregues, observa-se que o transporte dos produtos e/ou distribuição apresenta-se como fator crucial na determinação do nível de serviço ofertado aos clientes, tendo em vista que este é o setor responsável pelo contato direto com o ponto de consumo final. Logo, o estudo de caso levantou aspectos que foram fundamentais para apontar oportunidades de melhoria na distribuição de produtos para otimizar a utilização dos recursos e reduzir distâncias percorridas, combustíveis e outros custos relacionados à distribuição.

Por outro lado, sabe-se que dentro da distribuição, a empresa pode fazer algumas intervenções que podem acarretar em soluções não eficientes, o que significa um aumento desproporcional dos custos logísticos. No caso estudado, a organização precisa, também, desenvolver ações para evitar desperdícios com entregas perdidas a clientes mantendo contato com o mesmo antecipadamente, pois, este é um grave problema, que torna onerosa a logística atual da empresa.

Portanto, o artigo cumpriu o papel de disseminar aplicações da técnica de melhoramento das rotas dos veículos em empresas, ora denominado método de Clarke-Wright. Tal fato reforça a realidade de que em muitos sistemas de distribuição, a disposição dos veículos da forma correta é muito importante para atender melhor os clientes. 


\title{
Application of the Clarke and Wright method in solving routing problems: a case study
}

\begin{abstract}
The logistics of product distribution consists of taking the right products, to the right place, at the exact moment and with the level of service desired by the consumer, with the least possible cost and for that he makes use of heuristic methodologies for building roadmaps and deliveries of products. Knowing that any organization is capable of doing some interventions that can lead to inefficient solutions, which can mean a disproportionate increase in logistics costs. In this context, logistics plays an important role in the development of the organization. In order to optimize the delivery of products from a plant located in the city of Petrolina-PE, this research presents the use of routing tools combined with the geographic information system to optimize the delivery of products from a plant located in the city of Petrolina-PE. The Clarke and Wright heuristics were applied and the results confirmed their successful application in order to improve operational efficiency by reducing vehicle displacements to meet demands of $40 \%$.
\end{abstract}

KEYWORDS: Heuristics. Routing. Distribution. 


\section{REFERÊNCIAS}

ARAÚJO, R. R. Um Modelo de Resolução para o Problema de Roteirização em Arcos com Restrição de Capacidade. Dissertação (Mestrado) - Universidade Federal do Rio Grande do Sul, UFRGS, Porto Alegre. 2003, pp. 18-21.

ARBACHE, F. S., et al. Gestão de Logística, distribuição e trade marketing. Rio de Janeiro: Editora FGV, 2004.

BALLOU, R. H. Gerenciamento da cadeia de suprimentos/logística empresarial. 5. ed. Porto Alegre: Bookman: 2006. 616 p.

BARTH, M. B.; MICHEL, F. D. Dimensionamento de uma frota de veículos com foco na redução de custos: Estudo de caso. 2012. Disponível em: <http://www.lume.ufrgs.br/bitstream/handle/10183/65663/000858006.pdf?seq uence=1>. Acesso em: 09 fev. 2018.

BELFIORE, P. P.; FÁVERO, L. P. L. Problema de roteirização de veículos com entregas fracionadas: revisão da literatura. In: XIII SIMPEP, 2006, Bauru. Anais... Bauru: 312, 2006. Disponível em:

<http://www.simpep.feb.unesp.br/anais/anais_13/artigos/674.pdf >. Acesso em: 10 fev. 2018.

BERTAGLIA, P. R. Logística e gerenciamento da cadeia de abastecimento. São Paulo: Saraiva, 2009.

BOWERSOX, D. J. Logística Empresarial: O Processo De Integração Da Cadeia De Suprimento. Tradução Equipe do Centro de Estudos em Logística. - São Paulo: Atlas, 2001.

BOWERSOX, D. J; CLOSS, D. J. Logística Empresarial: o processo de integração da cadeia de suprimentos. 1. ed. São Paulo: Atlas, 2007.

BRASIL. Agência nacional de energia elétrica. ENERGIA SOLAR. 2003. Disponível em: <http://www2.aneel.gov.br/aplicacoes/atlas/pdf/03-Energia_Solar(3).pdf>. Acesso em: 9 fev. 2018.

CHABEREK, M. (ed.). Micro-and macroeconomic aspects of logistic support. (in Polish) Gdansk: University of Gdansk, (2002).

CHING, H. Y. Gestão de Estoques na cadeia de logística integrada. São Paulo: Atlas, 2001. 
CHRISTOPHER, M. Logistics \& Supply Chain Management. (4th edition), Pearson Education Limited, London. 2011.

CLARKE, G.; WRIGHT, J.W. Scheduling of Vehicles from a Central Depot to a Number of Delivery Points. Operations Research, v.12, n.4, p.568 - 581, 1964. crossref

CONCEIÇÃO, S. V. et al. Impactos da utilização de roteirização de veículos em um centro de distribuição: um estudo de caso. In: Congresso Brasileiro De Engenharia De Produção, 24, 2004, Florianópolis. Anais... Florianópolis: ABEPRO, 2004.

CORDEAU, J. F.; DESAULNIERS, G.; DESROSIERS, J.; SOUMIS, F. Vehicle Routing Problem (VRP) with Time Windows. SIAM Monographs on Discrete Mathematics and Applications. 2002. Disponível em: < https://www.researchgate.net/publication/229839571_VRP_with_Time_Window s> Acesso em 02 mai 2018. crossref

DALMÁS, S. A logística de transporte agrícola multimodal da região oeste do Paraná. Dissertação (Mestrado em Desenvolvimento Regional e Agronegócio) Programa de Pós -Graduação em Desenvolvimento Regional e Agronegócio. Toledo (PR): UNIOESTE, 2008.

FAULIN J., SAROBE P., SIMAL J.: The DSS LOGDIS Optimizes Delivery Routes for FRILAC's Frozen Products. Interfaces. Vol. 35, No. 3, 2005, pp. 202-214. crossref

FONSECA, J. J. S. Metodologia da pesquisa científica. Fortaleza: UEC, 2002. Apostila. Disponível em: <http://www.ia.ufrrj.br/ppgea/conteudo/conteudo2012-1/1SF/Sandra/apostilaMetodologia.pdf>. Acesso em: 10 fev. 2018.

GAMA, M. B. Roteirização de veículos: implementação e melhoria do método de Clarke e Wright. 93 f. TCC (Graduação) - Curso de Engenharia de Produção, UNIVASF, Juazeiro, 2011.

GASNIER, D. I G. A dinâmica dos estoques: guia prático para planejamento, gestão de materiais e logística. São Paulo: IMAM, 2002. 316p.

KAMINSKI, L. A. Proposta de uma Sistemática de Avaliação dos Custos Logísticos da Distribuição Física: o caso de uma Distribuidora de Suprimentos Industriais. 2004. Dissertação (Mestrado) - Curso de Mestrado Profissionalizante em Engenharia - Ênfase em Logística, UFRGS, Porto Alegre. 131p. 
LAPORTE, G.; M, GENDREAU; J.Y. P. F. SEMET. Classical and modern heuristics for the vehicle routing problem. International Transactions in Operational Research, v.7, n4/5, pp. 285-300, 2002. crossref

LUNA, M. M. M.; BELLOMUSTO, M. P.; MONHO, M. C. B. Problema De Roteirização Em Empresa Do Setor Alimentício: uma aplicação do método de CLARKE e WRIGHT. In: Congresso Brasileiro De Engenharia De Produção, 35. 2015, Fortaleza. Anais... . Fortaleza: ABEPRO, 2015. Disponível em: <http://www.abepro.org.br/biblioteca/TN_STO_206_222_28144.pdf>. Acesso em: 06 fev. 2018.

LUNA, M. M. M.; BELLOMUSTO, M. P.; MONHO, M. C. B. Problema de roteirização em empresa do setor alimentício: uma aplicação do método de clarke e wright. In: ENEGEP, 29., 2015, Fortaleza. Anais... Fortaleza: 2015.

LYSGAARD, J. Clarke \& Wright's Savings Algorithm. 1997. Disponível em: $<$ http://pure.au.dk/portal-asbstudent/files/36025757/Bilag_E_SAVINGSNOTE.pdf>. Acesso em: 16 fev. 2018.

MICHEL, F. D.; SENNA, L. A.; SENNA, E. T. P. Os desafios do financiamento de projetos e megaprojetos de transporte. Congresso de pesquisa e ensino em transportes. XXV ANPET, 2011.

NOVAES, A. G. Logística e Gerenciamento da Cadeia de Distribuição. Rio de Janeiro: Elsevier, 2007.

OSMAN, I. H. Metastrategy Simulated Annealing and Tabu Search Algorithms for the Vehicle Routing Problem. Annals of Operations Research, vol. 41, p. 421-451, 1993. crossref

PEREIRA, D. da S.; RONCONI, D. P. Modelo de distribuição física em uma indústria alimentícia. 2004. 98 f. TCC (Graduação) - Curso de Engenharia de Produção, Escola Politécnica da Universidade de São Paulo, São Paulo, 2004.

PLATT, A. A.; NUNES, R. da S. Logística na cadeia de suprimentos. Florianópolis: Departamento de Ciências da Administração/ Ufsc, 2007. 88 p.

PRADO, J. R.; BARROS, J. D. Cold Chain Management: Análise da Roteirização na Distribuição de Sorvetes. 2014. 87 f. TCC (Graduação) - Curso de Engenharia de Produção Com Ênfase em Controle e Automação, Eletrônica, Universidade Tecnológica Federal do Paraná, Ponta Grossa, 2014. 
RODRIGUES, L. F. et al. Aplicação da heurística de clarke wright em uma transportadora de médio porte. In: Simpósio Brasileiro De Pesquisa Operacional, 37, 2005, Gramado. Anais... . Gramado: SBPO, 2005. Disponível em: <http://www.din.uem.br/sbpo/sbpo2005/pdf/arq0271.pdf>. Acesso em: 06 fev. 2018.

SANTOS, A. V. N. dos; FELIX, L. B.; VIEIRA, J. G. V. Estudo da logística de distribuição física de um laticínio utilizando lógica fuzzy. Produção, [s.I.], v. 22, n. 3, p.576-583, ago. 2012. Fap UNIFESP (SciELO). crossref

SANTOS, R. L.; LEAL, J. E. Solução de um problema de roteirização com janelas de tempo através de um algoritmo de múltiplas colônias de formigas. Transportes, Xxx, v. 15, n. 2, p.5-16, dez. 2006. crossref

SILVA, L. F. K. Distribuição Física De Produtos Em Uma Empresa De Fast Food. 2015. 93 f. TCC (Graduação) - Curso de Engenharia de Transportes e Logística, Universidade Federal de Santa Catarina, Joinville, 2015. Disponível em: <https://repositorio.ufsc.br/xmlui/bitstream/handle/123456789/157167/TCC_Co rrigido Luiza Fuhrmann.pdf?sequence=1\&isAllowed=y>. Acesso em: 16 jan. 2018.

WU, L. O problema de roteirização periódica de veículos. 109 f. Dissertação (Mestrado) - Curso de Engenharia de Transportes, Escola Politécnica de Veículos, Escola Politécnica da Universidade de São Paulo - Usp, São Paulo, 2007. crossref

YIN, R. K. Estudo de caso: planejamento e métodos. 4. ed. Porto Alegre: Bookman, 2010.

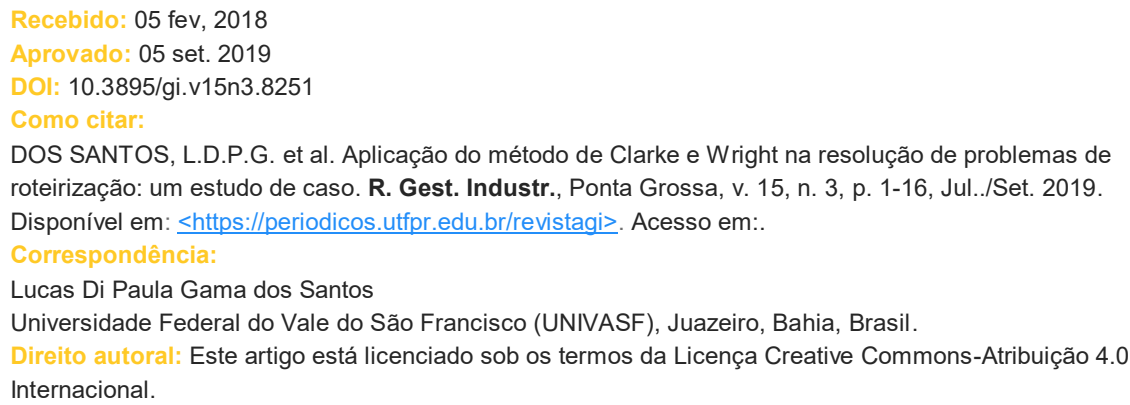

